\title{
PERDÓN, INOCENCIA Y CASTIGO. NIETZSCHE Y EL DERECHO PENAL
}

\author{
Juan Manuel Medrano Ezquerro \\ Universidad de La Rioja \\ uanmanuel310@gmail.com
}

\begin{abstract}
RESUMEN: Nietzsche criticó agudamente el sistema judicial de su época. Su denuncia acerca de los procedimientos penales y sus justificaciones es implacable. Mas, para comprender su postura es necesario retomar dos asuntos capitales de su filosofía: su concepción del «perdón» y la defensa de la «inocencia del ser». A partir de ahí, el rastreo genealógico de la penalidad, inseparable de la construcción moral de las sociedades, explica el advenimiento de las modernas formas de castigo.
\end{abstract}

Palabras clave: Nietzsche, Derecho, castigo, culpa, pecado, genealogía, moralidad, perdón, inocencia, Foucault.

\section{FORGIVENESS, INNOCENCE AND PUNISHMENT. NIETZSCHE AND THE CRIMINAL LAW}

\begin{abstract}
Nietzsche did an acute criticism of the judicial system of his time. His impeachment about the criminal proceedings and their justification was ruthless. However, if we want to understand his approach, it will be necessary to review two key concepts of his philosophical thinking: the way he elaborated the ideas of the "forgiveness" and the defense of "the innocence of being". The genealogical tracing of penalty, which should be understood as inseparable of the moral construction of a society, explains eventually the rising of the modern ways of punishment.
\end{abstract}

Keywords: Nietzsche, Law, punishment, guilt, sin, genealogy, morals, forgiveness, innocence, Foucault. 


\section{Introducción}

$$
\begin{array}{r}
\text {... ¿Por qué no ayudáis a erradicar del mundo esa mala hierba } \\
\text { que crece por todas partes: la idea de castigo [...] ¡Parece } \\
\text { como si la educación de la humanidad hubiese estado dirigida } \\
\text { hasta ahora por la imaginación de carceleros y verdugos! } \\
\text { Aurora, \#13 }
\end{array}
$$

Intentaremos aproximarnos en estas páginas a un aspecto de la filosofía de Nietzsche relativamente poco tratado en la abundante literatura sobre este autor. Nos referiremos al conjunto de sus opiniones sobre la penalidad y el derecho penal. Sabido es que Nietzsche no fue un jurista, pero, si profundizamos en sus textos de todas las épocas, advertimos allí toda una filosofía del derecho. Para nosotros, comprender su filosofía de la justicia requiere el acercamiento a dos asuntos capitales de su filosofía. Nos referimos a su noción de «perdón» (y «donación»), polémicamente confrontada con su interpretación del perdón cristiano. Y, en segundo lugar, la doctrina de la total irresponsabilidad de las acciones humanas (dicho de otra manera: su defensa de la no libertad de la voluntad). Bajo la luz arrojada por ambas cuestiones, el análisis nietzscheano de la justicia, los castigos penales y las formas punitivas del Estado moderno adquirirán otra luz.

El grueso de sus posiciones sobre el derecho, la justicia y la penalidad se compendian en su obra más sombría, La genealogía de la moral, aunque hay referencias fundamentales en muchos otros pasajes de su obra, especialmente en Aurora, donde explica con detalle la génesis de las primitivas formaciones sociales bajo el epígrafe de la «moralidad de las costumbres». Para situar correctamente el análisis nietzscheano de las formas de justicia y penalidad decimonónicas es muy útil acudir a ciertos textos de Michel Foucault (especialmente La verdad y las formas jurídicas) que -a nuestro juicio- resultan complementarios y aclaratorios de las tesis del pensador alemán.

El resultado de los análisis nietzscheanos provoca la sensación de que el pensador - desde la afirmación sin ambages del carácter activo y positivo del derechopide a la sociedad de su tiempo que cambie radicalmente su manera de «castigar», que elimine el sinsentido de una pena en la que se superponen decenas de intenciones periclitadas, absurdas, crueles e ineficaces. Si de ahí se interpreta una concepción progresista del derecho y de la justicia, habremos alimentado una más de las inacabables polémicas que desde hace decenas de años pretenden evaluar a este autor bajo las categorías, poco satisfactorias, de «progresismo» o «reacción».

\section{Los conceptos nietzscheanos de "perdón»e «inocencia del ser»}

\subsection{El concepto de perdón. La crítica a los conceptos cristianos de "pecado» y} «confesión»

Los conceptos nietzscheanos de «perdón», «donación» y «olvido», instrumentos clave para liberar al hombre de la carga del pasado, del «fue», de la culpa, 
forman parte de su ocupación filosófica a lo largo de su vida e integran una parte importante del núcleo discursivo de su Zaratustra. Veremos cómo este planteamiento adquiere nueva luz cuando lo confrontamos con la crítica al perdónconfesión cristianos y, como se evidenciará después, con el aparato punitivo y represor (también susceptible de "gracia») que se arroga el Estado moderno.

Algunos estudios recientes relacionan el concepto de «perdón» en Nietzsche con el de otros autores que, parcialmente al menos, parecen interpretarlo en parecido sentido. Es el caso de H. Arendt y J. Derrida. ${ }^{1}$ Resulta de sentido común relacionar los conceptos «perdón» y «cristianismo». Arendt lo hace explícitamente en algunos textos, afirmando que fue Jesús quien primero instituyó esta novedad en el devenir de la historia:

El descubridor del papel del perdón en los asuntos humanos fue Jesús de Nazaret. El hecho de que hiciera este descubrimiento en un contexto religioso y lo articulara en un lenguaje religioso no es razón para tomarlo con menos seriedad en un sentido estrictamente secular ${ }^{2}$.

Esta novedad evangélica estará Ilamada a tener una importancia decisiva, al mismo tiempo que se transformará profundamente con la evolución institucional del cristianismo. Tal afirmación tiene una enorme cantidad de citas evangélicas en la que fundamentarse, pues la noción de "perdonar» recorre enteramente las predicaciones y sermones de Jesús (Mateo 5, 23-24; Lucas 17, 3). Los conceptos de perdón y «don» gratuito que, para algunos intérpretes, aproximan a Jesús y a Zaratustra, no son idénticos en la acepción evangélica y en la Iglesia histórica: el perdón en Jesús no tiene contrapartidas, ni somete al perdonado al perdonador; es absoluto -mediando el arrepentimiento-, lo que posibilita un nuevo comienzo para cualquier criatura. Aunque tal vez pueda ser este el fin de la confesión cristiana, Nietzsche no cree que en su concreción histórica conserve el carácter que tenía en el Jesús judío.

¿Qué caracteriza al perdón institucional cristiano, ligado a la confesión y a la dirección espiritual del sacerdote? Prácticamente a este agudo problema dedica Nietzsche el Título III de La genealogía de la moral ( ¿Qué significan los ideales ascéticos?»). A lo largo de sus páginas se refleja la doble dirección que toma la asunción por el sacerdote de la tutoría espiritual de ser sufriente: asegura la vida y a la vez la encadena, en esa doble y ambivalente realidad de que para sanar enferma primero 3 .

1. Es la tesis de Lemm, V. (2011): Nietzsche y el pensamiento político contemporáneo.

2. Arendt H., (1993), p. 258.

3. Dice Nietzsche: "... el ideal ascético nace del instinto de protección y de salud de una vida que degenera [...] Ocurre, por tanto, lo contrario de lo que piensan sus adoradores, -en él y a través de él [el ideal ascético] la vida lucha con la muerte y contra la muerte, el ideal ascético es una estratagema en la conservación de la vida..." (Nietzsche, 1978, pp. 139-140). 
Relacionábamos el concepto de perdón en Arendt con el de Nietzsche. La conexión en la intención de ambos puede plantearse del siguiente modo: hacer posible un nuevo comienzo para el hombre. Arendt, cuyo objetivo era devolver a la política una nobleza perdida, encuentra en el perdón la única posibilidad de revertir lo que a menudo llama "las consecuencias de la acción y del discurso"; esto es, la imprevisibilidad de las acciones humanas y de sus resultados, así como la irreversibilidad de los procesos que desencadenan ${ }^{4}$. Nietzsche, por su parte, trata de liberar al ser humano de la más pesada cadena que arrastra, el binomio culpa-pasado:

Ninguna acción puede ser aniquilada: ¡cómo podría ser anulada por el castigo! Lo eterno en el castigo Ilamado 'existencia' consiste en esto, ¡en que también la existencia tiene que volver a ser eternamente acción y culpa! [...] Y la justicia misma consiste en aquella ley del tiempo según la cual éste tiene que devorar a sus propios hijos: así predicó la demencia ${ }^{5}$.

La intención de Nietzsche podría resumirse en la fórmula de Savater: «desculpabilizar la voluntad» ${ }^{6}$. Los instrumentos del filósofo para conseguir redimir al hombre del ciclo destructor de la culpa, el pecado y el castigo son el perdón, la donación y el olvido. El perdón en Nietzsche -como en Derrida- debe ser incondicional, liberador de toda culpa pasada, debe ser absoluta «donación» sin contrapartidas y establecer el olvido completo que devuelve a la inocencia.

Mas, el perdón que Nietzsche propone, no se corresponde con el perdón institucional que la Iglesia histórica ejecuta en el acto de la confesión; y tampoco es verdadero perdón el que institucionaliza el Estado moderno en su práctica judicial. ¿Cuál es la crítica de Nietzsche al concepto cristiano de «perdón»? En primer lugar, éste se genera en toda una economía de poder ejercida por el sacerdote. En segundo lugar, porque -siguiendo el razonamiento de Lemmel perdón cristiano:

...no puede quebrar el ciclo de la venganza. La práctica cristiana del perdón no redime el pasado, sino que provoca sentimientos de resentimiento, odio y venganza hacia el pasado [...] La práctica cristiana del perdón no puede donar. Su donación no eleva la vida animal humana, sino que la envenena. En contraste, Nietzsche aprueba solamente aquellas prácticas de perdón que entienden cómo redimir el pasado y tienen su origen en la donación ${ }^{7}$.

\footnotetext{
4. Arendt H. (1993), p. 256.

5. Nietzsche (1978), pp. 204-206.

6. Savater F. (2000).

7. Lemm (2011), pp. 112-113.
} 
En conclusión, siguiendo el razonamiento de la autora:

Según la crítica de Nietzsche a la noción cristiana de perdón, ésta no redime al individuo y a la comunidad del pasado, sino que fomenta su dependencia de instituciones que reclaman para sí mismas el poder de administración del perdón. Nietzsche sospecha que tras este reclamo de poder reside el deseo de dominar y controlar la vida del individuo y de la comunidad. Según esta perspectiva, el perdonar instituye una desigualdad entre el que perdona y el que es perdonado. Este perdonar presupone entonces una superioridad moral que autoriza a quien perdona a juzgar y evaluar a quien pide perdón para determinar si este último puede ser realmente perdonado [...] En la crítica de Nietzsche a la noción cristiana de perdón, esta última refleja una transacción económica formada, por un lado, por la atribución de culpa y de responsabilidad moral y, por otro, por una restitución de justicia través del juicio y el castigo ${ }^{8}$.

Tal vez ahora podamos comprender mejor la virulencia de Zaratustra contra todos aquellos que parecen empeñados en uncir al ser humano con una carga inextirpable de culpabilización; quienes, por lo general, son encarnados por la figura sacerdotal (Zaratustra: «De los trasmundanos»), aunque a menudo toman la forma de la «justicia» moderna:

Las cosas están reguladas éticamente sobre la base del derecho y el castigo. Oh, ¿ dónde está la redención del río de las cosas y del castigo llamado 'existencia' Así predicó la demencia.

¿Puede haber redención si existe un derecho eterno? ¡Ay, irremovible es la piedra 'fue': eternos tienen que ser también todos los castigos' Así predicó la demencia ${ }^{9}$.

La alternativa de Zaratustra a la vieja fórmula eclesial y estatal consiste en perdón, donación y olvido ${ }^{10}$; sólo ellos liberan la conciencia y redimen al tiempo, haciendo posible siempre una re-novación de la existencia sin culpa o, siguiendo la metáfora de las tres transformaciones del espíritu, dejar atrás al «camello» (deber), al «león» ("yo quiero") para llegar al «niño» ("yo soy"):

Inocencia es el niño, y olvido, un nuevo comienzo, un juego, una rueda que se mueve por sí misma, un primer movimiento, un santo decir sîn ${ }^{11}$.

8. Lemm (2011), pp. 115-116, remite a Humano II, \#68: «¿Se puede perdonar?».

9. Nietzsche (1978), pp. 205-206.

10. A propósito de esto dice Vanessa Lemm respecto a la «donación» nietzscheana: "una fuerza que interrumpe la economía de autopreservación llevándola a una economía de donación más allá de todo cálculo" (Lemm, 2011, p. 131).

11. Nietzsche (1978), p. 51. 


\title{
2.2. La doctrina de la inocencia e irresponsabilidad del ser
}

\author{
Culpar a otros de nuestras desdichas es una muestra de \\ ignorancia; culparnos a nosotros mismos constituye el \\ principio del saber; abstenerse de atribuir la culpa a otros o \\ a nosotros mismos es muestra de perfecta sabiduría. \\ Epicteto
}

El edificio jurídico de una sociedad es una de las bases fundamentales que sostienen el andamiaje de una civilización. La tradición legal, el Derecho romano y posteriores, constituyen las arquitecturas que definen el horizonte del mundo occidental. Dicho de otra manera, ninguna sociedad, ni siquiera las más injustas o a-legales, se mantienen en pie sin un edificio normativo, aunque provenga del ámbito de lo religioso, por ejemplo. Y, en realidad, es un solo axioma, una afirmación única y concreta la que otorga sentido a todo el aparato judicial en el que nos desenvolvemos: el hombre decide libremente la dirección de sus actos; es decir, nuestro mundo se define por la noción de «libre albedrío». Nadie, cualquiera que fuese su ideología, dejaría de observar que sin tal premisa esencial de la sociedad ésta se desmoronaría. Nietzsche -aunque no el único- es uno de los filósofos de la no-libertad de la voluntad. Tratemos, pues, de ver los argumentos nietzscheanos en pro de la inocencia del ser y las consecuencias que se habrían de extraer para la práctica de la justicia penal.

La no-libertad de la voluntad

Su doctrina sobre la no-libertad de la voluntad se fundamenta en el marco más general de su crítica a la metafísica, cuyos ejes principales se vertebran en el libro primero de Humano, demasiado humano. Allí son severamente cuestionadas las tradicionales categorías de «sustancia» y «agente». Nietzsche niega la posibilidad real -salvo en lenguaje- de separar «acción» y "agente»: "no hay ningún «ser» detrás del hacer, del actuar, del devenir; «el agente» ha sido ficticiamente añadido al hacer, el hacer es todo..." (Nietzsche, 1978). El desarrollo de la civilización aceptó y necesitó distinciones que no son reales; ni siquiera la noción de «sujeto» deja de ser una entelequia metafísica necesaria para la vida, uno de los errores necesarios o verdades irrefutables de las que Nietzsche habla como trampolín del despegue del animal hacia el humano.

Dos ideas clave, diseminadas en sus múltiples obras, resultan para nosotros relevantes a la hora de determinar la base filosófica sobre la que construye su teoría del derecho y la penalidad. Sucintamente podrían resumirse así:

- El error más importante de toda la metafísica y consiguientemente de toda moral y todo derecho es la creencia en la noción de «libre albedrío». 
- La doctrina de la libertad de la voluntad es una imposición de las castas dominadoras, en el lenguaje, en la moral, y en el derecho y la consecuencia es un poder castigar. Acudamos a los textos que nos aclaran la primera afirmación:

La creencia en la libertad del albedrío es un error originario de todo lo orgánico [...]; la creencia en sustancias incondicionadas y en cosas iguales es asimismo un error originario, no menos antiguo, de todo lo orgánico. Pero, en la medida en que toda metafísica se ha ocupado primordialmente de la sustancia y de la libertad del albedrío, cabe definirla como la ciencia que trata de los errores fundamentales del hombre, pero como si fuesen verdades fundamentales ${ }^{12}$.

Aún más nítida es la posición nietzscheana en el aforismo La fábula de la libertad inteligible:

... Descúbrese entonces por último que este ser tampoco puede ser responsable, por ser una consecuencia entera y absolutamente necesaria, y derivar de elementos e influjos de cosas pasadas y presentes; por tanto, que al hombre no puede hacérsele responsable de nada, ni de su ser, ni de sus motivos, ni de sus actos, ni de sus efectos. Se llega con ello al reconocimiento de que la historia de los sentimientos morales es la historia de un error, del error de la responsabilidad, el cual estriba en el error de la libertad de albedrío [...] Nadie es responsable de sus actos ni de su ser; juzgar es tanto como ser injusto. La tesis es tan clara como la luz del sol y, sin embargo, aquí todo el mundo prefiere volver a la sombra y a la falsedad, por temor a las consecuencias ${ }^{13}$.

Esencial es igualmente el aforismo Irresponsabilidad e inocencia:

La plena irresponsabilidad del hombre respecto a sus actos y a su ser es la píldora más amarga que tiene que tragar quien persigue el conocimiento cuando se ha habituado a ver en la responsabilidad y el deber el título de nobleza de su humanidad [...] Los grados de capacidad y juicio deciden a qué se deja cada cual arrastrar por ese anhelo; cada sociedad, cada individuo, tienen constantemente presentes una jerarquía de los bienes según la cual determinan sus actos y juzgan los de los demás [...] Todo es necesidad: así reza el nuevo conocimiento; y este conocimiento mismo es necesidad. Todo es inocencia; y el conocimiento es el camino hacia la comprensión de esta inocencia ${ }^{14}$.

12. Nietzsche (2001), p. 54.

13. Nietzsche (2001), pp. 67-68.

14. Nietzsche (2001), p. 54. 
Años después, nada diferente dirá Nietzsche en Crepúsculo de los ídolos:

¿Cuál puede ser nuestra única doctrina? Que al ser humano nadie le da sus propiedades, ni Dios, ni la sociedad, ni sus padres y antepasados, ni él mismo (el sinsentido de esta noción que aquí acabamos de rechazar ha sido enseñado como 'libertad inteligible' por Kant, acaso ya también por Platón). Nadie es responsable de existir, de estar hecho de este o de aquel modo, de encontrarse en estas circunstancias, en este ambiente. La fatalidad de su ser no puede ser desligada de la fatalidad de todo lo que fue y será 15 .

Parece evidente -a la luz de tales textos- que la doctrina de Nietzsche acerca de la ilusión humana de poseer una voluntad «libre» constituye uno de los elementos nucleares de su pensamiento. Evidentemente, sus consecuencias no afectan únicamente al ámbito de la moral y del derecho, aunque sean las que vamos a tratar aquí. Él es consciente de que los creativos procedimientos del «error» han sacado a los hombres de la inmanencia del reino animal; que las consecuencias de este proceso han devenido tan ricas, complejas y productivas que han producido un animal interesante; que erradicar la concepción de la libre voluntad humana costará lo indecible, aunque sea la ciencia la que irá haciendo evidente el reino de la necesidad.

Conocido el error de la voluntad libre, cabe preguntarse: ¿cómo surgió? ¿De qué suelo brotó? ¿Quién lo introdujo en el mundo?

La imposición desde arriba de la noción de «responsabilidad»

La idea de que la noción de libertad de la voluntad es una imposición de las clases dominantes, se puede rastrear en varios textos de Nietzsche. Foucault ha reflexionado a fondo sobre ello en su Nietzsche, Freud, Marx. Así:

No hay para Nietzsche un significado original. Las mismas palabras no son sino interpretaciones, a todo lo largo de su historia, antes de convertirse en signos, interpretan, $y$ tienen significado finalmente porque son interpretaciones esenciales. [...] Es también en este sentido en el que Nietzsche dice que las palabras fueron siempre inventadas por las clases superiores; no indican un significado, imponen una interpretación ${ }^{16}$.

Para rastrear el origen de la idea de libertad de la voluntad deberemos -siguiendo las consignas de Foucault- no preguntarnos por el qué, sino por el

15. Nietzsche (1979), p. 69.

16. Foucault (1981), p. 37. 
quién impone la interpretación ${ }^{17}$. El orden de la imposición de los valores al conjunto social no puede provenir sino desde arriba, de arriba abajo; es el señor quién determina lo «bueno» y lo «malo». Ésta es la forma de valoración activa (la misma fuerza que afirmará el «derecho» sobre la tierra), frente a la valoración reactiva, aquella que procede del resentimiento:

...fueron «los buenos» mismos, es decir, los nobles, los poderosos, los hombres de posición superior y elevados sentimientos quienes se sintieron y se valoraron a sí mismos y a su obrar como buenos, o sea como algo de primer rango, en contraposición a todo lo bajo, abyecto, vulgar y plebeyo ${ }^{18}$.

Y la conclusión de Nietzsche explícita la idea que venimos mostrando:

El derecho del señor a dar nombres llega tan lejos que deberíamos permitirnos el concebir también el origen del lenguaje como una exteriorización de poder de los que dominan ${ }^{19}$.

A partir de aquí, sigue Nietzsche, se impuso la tarea -bajo una lucha feroz contra la capacidad de olvido- de dotar al hombre de «responsabilidad», criando un animal al que le fuera lícito «hacer promesas», para lo cual fue necesario:

...hacer antes al hombre, hasta cierto grado, necesario, uniforme, igual entre iguales, ajustado a regla, y, en consecuencia, calculable (Nietzsche, 1978).

A través de los procedimientos nemotécnicos, bajo la presión constante de la crueldad, especialmente -dice Nietzsche- de la "dureza de las leyes penales", se consiguió ese hombre «responsable», predecible, capaz de vivir en sociedad, aunque también apareció en la tierra la flor más extraña y productiva, la llamada «mala conciencia»:

Yo considero que la mala conciencia es la profunda dolencia a que tenía que sucumbir el hombre bajo la presión de aquella modificación, la más radical de todas las experimentadas por él, -de aquella modificación ocurrida cuando el hombre se encontró definitivamente encerrado en el sortilegio de la sociedad y de la $\operatorname{paz}^{20}$.

Bajo estas bases filosóficas es posible acometer las reflexiones nietzscheanas acerca de la justicia, el derecho y el castigo.

17. Foucault (1981), p. 40.

18. Nietzsche (1978), p. 31. Esta idea está perfectamente documentada por el profesor F. Rodríguez Adrados a propósito de la moral aristocrática en la Grecia antigua. (Rodríguez Adrados, 2007).

19. Nietzsche (1978), p. 31.

20. Nietzsche (1978), p. 95. 


\section{La justicia y la penalidad en Nietzsche}

3.1. Origen y evolución de la penalidad: «moralidad de las costumbres» y genealogía de la moral

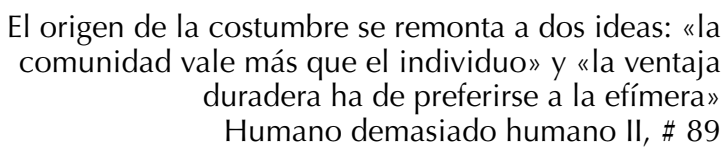

Nietzsche acomete en numerosos aforismos la relación de temas que venimos comentando; sin embargo, hay dos conjuntos de reflexiones en su obra imprescindibles para interpretar su filosofía del derecho: en Aurora, bajo la denominación de "Moralidad de las costumbres» y en la Genealogía de la moral, especialmente en su $2^{\circ}$ Tratado.

Para él los orígenes del derecho y del castigo penal se ubican en el ámbito mismo del nacimiento de la «moral», tema nuclear en su obra. En paralelo con la moralidad surgen los problemas acerca del origen de la sociedad y del Estado, en tanto estas instancias serán las que se apropien de un derecho punitivo que había permanecido históricamente en manos de los particulares y familiares del agraviado. Por ello, habremos de dedicarles alguna reflexión.

La aplicación de los castigos en épocas pretéritas se producía inicialmente en el ámbito de lo privado. Las condiciones en las que se podía ejercer la violencia contra el infractor pertenecían al marco general que Nietzsche denomina «moralidad de las costumbres». ¿Qué características presenta aquel periodo que condicionaban todo el ejercicio del "castigo»? Enumerémoslas brevemente: la dictadura de la costumbre como ley inexorable, el papel crucial del «miedo», el peligro de todo comportamiento individual, es decir, la supremacía absoluta del grupo sobre el individuo:

En todos los lugares donde existe una comunidad y, por consiguiente, una moral fundada en las costumbres, impera igualmente la idea de que el castigo debido a la violación de las costumbres recae, sobre todo, en la comunidad [...] Ésta siente la culpa del individuo como culpa colectiva suya y reconoce el castigo del individuo como un castigo que recae sobre ella ${ }^{21}$.

Parece evidente, a la vista de tales presupuestos, que la primera forma de castigo responde a unas comunidades inseguras, incipientes, que no han deslindado aún los conceptos de «acto» y «responsabilidad» individual, ya que entienden que la falta de uno de los suyos constituye una afrenta a las divinida-

21. Nietzsche (2000), p. 69. 
des que mancha al grupo entero ${ }^{22}$. En una organización social débil, en formación, cualquier suceso que debilite o amenace la cohesión grupal se significa como un gran peligro para toda la comunidad. Así entendido, el proceso que Nietzsche determina en la evolución de los castigos penales es éste: cuánto más se fortalece y cohesiona una sociedad -dicho en su lenguaje, cuanto más se moraliza- menor necesidad tiene de recurrir a formas extremas de castigo. Un paso adelante se dará cuando el ámbito de la venganza y del castigo comience a regirse por una ley de reciprocidad, que analizará a fondo como relación acreedor-deudor.

La consecuencia de esa forma de vida primitiva, y el estado de guerra casi permanente en que se vive, hicieron que la crueldad formara parte esencial de la cohesión y solidez del grupo. Aunque sobre este fenómeno se extiende especialmente en La genealogía, sus obras anteriores apuntan ya la importancia de la crueldad en el devenir de la humanidad:

¿Cuál es el mayor placer que pueden experimentar unos hombres que viven en estado constante de guerra, en esas pequeñas comunidades rodeadas siempre de peligros, donde impera la moral más estricta, es decir, para las almas vigorosas, sedientas de venganza, rencorosas, suspicaces, preparadas para los acontecimientos más espantosos, endurecidas por las privaciones y por la moral? El placer de la crueldad [...] La comunidad se robustece contemplando actos de crueldad y puede superar la tenebrosa sensación de miedo y de cautela continuas. La crueldad es, pues, una de las más antiguas alegrías festivas de la humanidad ${ }^{23}$.

\section{La dialéctica acreedor/deudor}

Éste es uno de los fragmentos esenciales de Nietzsche para comprender el problema del origen de la pena y del derecho:

Durante el más largo tiempo de la historia humana se impusieron penas no porque al malhechor se le hiciese responsable de su acción, es decir, no bajo el presupuesto de que sólo al culpable se le deban imponer penas, sino, más bien, a la manera como todavía ahora los padres castigan a sus hijos, por cólera de un perjuicio sufrido, la cual se desfoga sobre el causante, -pero esa cólera es mantenida dentro de unos límites y modificada por la idea de que todo perjuicio tiene su equivalente y puede ser realmente compensado, aunque sea con un dolor del causante del perjuicio. ¿De dónde ha sacado su fuerza esta idea antiquísima,

22. Como acertadamente vio R. Girard (1983): La violencia y lo sagrado.

23. Nietzsche (2000), pp. 73-74. 
profundamente arraigada y tal vez ya imposible de extirpar, la idea de una equivalencia entre perjuicio y dolor? Yo ya lo he adivinado: de la relación contractual entre acreedor y deudor, que es tan antigua como la existencia de «sujetos de derechos» y que, por su parte, remite a las formas básicas de compra, venta, cambio, comercio y tráfico ${ }^{24}$.

Nietzsche remite en este tratado segundo al doble sentido de «schuld» («culpa» y «deuda»). Así, el primer castigo se ejecutaba como explosión de cólera. Estamos en otra fase cuando se encuentra para cada «agravio» un «equivalente»; pero hemos de pensar que esto sólo puede ocurrir con una sociedad ya asentada, con un poder (estatal) reconocido por todos. Tal poder actúa ya como una fuerza reguladora, calculadora: a tanta agresión, tanto derecho a «compensación»... Estamos ya ante formas de derecho bien establecidas. Lo curioso es que la satisfacción penal primitiva parece obtenerse sobre todo en un ámbito psicológico, y no material (por ejemplo apropiándose de un cuerpo útil para el trabajo).

Si la satisfacción de poder descargar violencia sobre el deudor es realmente una "compensación» suficiente para el acreedor, hemos de pensar - dice Nietzsche- que una satisfacción así remite a una de las necesidades humanas más antiguas y arraigadas, aunque hoy nos produzca extrañeza: la necesidad de infligir dolor, el placer de causarlo, que se observa en la psicología más primitiva: "ver sufrir produce placer, hacer sufrir más placer aún" 25 .

Toda esa escrupulosidad y minuciosa regulación del castigo, de la cantidad a tomar del cuerpo del deudor, se relaja con la legislación romana:

El acreedor podía infligir al cuerpo del deudor todo tipo de ultrajes y torturas, por ejemplo, cortar de él la cantidad que pareciese proporcionada a la magnitud de la deuda: y ya tempranamente y en todas partes hubo a estos efectos estimaciones exactas conforme a Derecho -en ocasiones descendían a detalles tan minúsculos como estremecedores- de los distintos miembros y lugares del cuerpo. Considero que es ya un progreso, una prueba de una concepción jurídica más libre, más amplia de miras en sus cálculos, más romana, que la legislación de las XII tablas vigente en Roma decretara que era indiferente cuánto cortasen los acreedores en un caso semejante, «si plus minusve secuerunt, ne fraude esto ${ }^{26}$.

24. Nietzsche (1978), p. 72.

25. Nietzsche se explaya sobre otra interesantísima cuestión en la que no podemos entrar: la relación que existe entre crueldad y fiesta en todos los contextos de alegría colectiva hasta tiempos relativamente recientes (Nietzsche, 1978, pp. 75-76).

26. Nietzsche (1978) p. 73. 
Lo que irá ganando peso en la legislación penal de la sociedad es el siguiente principio: el delito es cada vez menos un delito contra particulares cuanto un acto contra toda la comunidad, en el sentido apuntado de acreedor/deuda. La sociedad otorga al individuo una serie de ventajas y seguridades; la infracción es una ruptura de la obligación de reciprocidad hacia esa comunidad; la potestad de ésta, entre otras, es la "expulsión», es decir, la devolución del deudor al estado de naturaleza ${ }^{27}$.

Recordemos que el otro sentido de la crueldad y de los castigos es interpretado por Nietzsche como la necesaria violencia ejercida sobre aquella humanidad incipiente para hacerle al hombre una «memoria», una nemotécnica, con objeto de que el ser humano que quiere vivir en comunidad pueda recordar seis o siete deberes bajo la vieja regla psicológica de que sólo lo que no deja de doler puede permanecer en la memoria ${ }^{28}$.

Las formas penales se van suavizando cuando las sociedades se fortalecen y cohesionan, y resulta menos probable vulnerarlas o dañarlas de manera grave. En una situación ya estatal el castigo penal va a dejar esas viejas formas de venganza familiar y va a ser gestionado por el monopolizador de la violencia institucional. El problema que va a surgir en las sociedades modernas es que se va a difuminar el sentido real de la pena, como veremos más adelante.

\section{El origen no contractual del Estado}

Recordemos brevemente que Nietzsche no tiene una concepción contractualista del origen del Estado. Siempre opinó contra la teoría rousseauniana de «contrato». El Estado sólo pudo aparecer como hecho de fuerza, como manifestación de una voluntad de poder; no poseyó legitimidad de origen ${ }^{29}$, sino que -como todas las cosas «grandes» en la tierra- fue construyendo esa legitimidad paulatinamente, en la medida en que fuerzas activas y no reactivas, controlarán el poder y determinarán el derecho, como vamos a ver a continuación. Un conocido texto aclara su postura:

27. Esta evolución -como veremos más adelante- también puede sufrir interrupciones históricas y darse situaciones de regresión a un derecho entre «particulares» (Foucault, 2005).

28. «Para que algo permanezca en la memoria se lo graba a fuego; sólo lo que no cesa de doler permanece en la memoria» [...] La dureza de las leyes penales nos revela cuánto esfuerzo le costaba a la humanidad lograr la victoria contra la capacidad de olvido. Nietzsche (1978), p. 69.

29. Como todo, como la propia moralidad, dice Nietzsche, está manchado de «sangre» en su origen: "Su comienzo, al igual que el comienzo de todas las cosas grandes en la tierra, ha estado salpicado profunda y largamente de sangre. ¿Y no sería lícito añadir que, en el fondo, aquel mundo no ha vuelto a perder nunca del todo un cierto olor a sangre y a tortura?" (Nietzsche, 1978, p. 74). 
El «Estado» más antiguo apareció, en consecuencia, como una horrible tiranía, como una maquinaria trituradora y desconsiderada, y continuó trabajando de ese modo hasta que aquella materia bruta hecha de pueblo y semianimal no sólo acabó por quedar bien amasada y maleable, sino por tener también una forma. He utilizado la palabra «Estado»: ya se entiende a qué me refiero -una horda cualquiera de rubios animales de presa, una raza de conquistadores y de señores, que, organizados para la guerra, y dotados de la fuerza de organizar, coloca sin escrúpulo alguno sus terribles zarpas sobre una población tal vez tremendamente superior en número, pero todavía informe, todavía errabunda. Así es como, en efecto, se inicia en la tierra el «Estado»: yo pienso que así queda refutada aquella fantasía que le hacía comenzar como un «contrato ${ }^{30}$.

\section{El derecho como fuerza «activa»}

Del mismo modo que Nietzsche afirma la irrupción violenta de formas de poder estable y duradero que llama «Estado», insiste en la paralela victoria de los instintos de la «justicia» que acompañan al hombre activo al establecer y dirigir tales Estados; es precisamente el triunfo de los instintos «activos» el que se plasma en el derecho, el que va a posibilitar poner un freno, un límite, a los actos de venganza propios del resentimiento y volver la justicia cada vez más «impersonal». El \#11 del tratado II de la Genealogía es particularmente explícito en este sentido:

Históricamente considerado, el derecho representa en la tierra la lucha precisamente contra los sentimientos reactivos, la guerra contra éstos realizada por poderes activos y agresivos, los cuales empleaban parte de su fortaleza en imponer freno y medida al desbordamiento de pathos reactivo y en obligar por la violencia a un compromiso. En todos los lugares donde se ha ejercido justicia, donde se ha mantenido justicia, vemos que un poder más fuerte busca medios para poner fin, entre gentes más débiles, situadas por debajo de él (bien se trate de grupos, bien se trate de individuos), al insensato furor del resentimiento, en parte quitándoles de las manos de la venganza el objeto del resentimiento, en parte colocando por su parte, en lugar de la venganza, la lucha contra los enemigos de la paz y el orden, en parte inventando, proponiendo $y$, a veces, imponiendo acuerdos, en parte elevando a categoría de norma ciertos equivalentes de daños, a los cuales queda remitido desde ese momento, de una vez por todas, el resentimiento ${ }^{31}$.

30. Nietzsche (1978) p. 98.

31. Nietzsche (1978) pp. 85-86. 


\subsection{La crítica de Nietzsche al sistema penal «burgués» (un análisis en perspec- tiva foucaultiana)}

¿Qué elementos componen el sistema penal «burgués» al que Nietzsche dedicará tantas críticas? Es necesario que penetremos en el sentido de la justicia que él observa en su siglo: sus procedimientos, su noción de verdad, la reacción que provoca en el delincuente, etc.

Parece evidente que el procedimiento penal busca siempre la obtención de la verdad a través del juicio, y que la revelación de tal verdad descansa sobre la noción -ya analizada- de la libertad de la voluntad para ejecutar, o no, el hecho delictivo. Pero, tal vez, antes de penetrar en la entraña del sistema penal burgués -y con objeto de situar con mayor precisión el sentido de las reformas penales en su evolución histórica- puede resultarnos útil acudir a algunos trabajos de Michel Foucault, con objeto de esclarecer cuestiones como las siguientes: ¿la noción de «verdad» en los procedimientos jurídicos ha sufrido desplazamientos históricos, y en qué sentido? ¿De dónde procede la forma de probación en el proceso judicial moderno? ¿Guarda aún relación la «confesión» cristiana con el procedimiento judicial? Y, ¿qué novedades, ya vigentes en la época de Nietzsche, había aportado la crítica de los ilustrados a los procedimientos judiciales y a la aplicación de los castigos penales?

La verdad y las formas jurídicas

Bajo la intención de establecer las formas cambiantes que ha ido adquiriendo la noción de «sujeto» (y subjetividad), por un lado, y la noción de «poder» por otro, Foucault confiesa la importancia que han tenido las prácticas judiciales para la "emergencia de nuevas formas de subjetividad", en su búsqueda de una "historia externa, exterior, de la verdad". Ciertas formas de esa verdad han de ser, en consecuencia, estudiadas, a partir de las prácticas judiciales y sus procedimientos, especialmente de la llamada «indagatio» ${ }^{32}$.

Foucault narra los desplazamientos de la forma de demostración de la verdad desde los griegos: desde el juramento, como fórmula de establecimiento de la verdad, hasta la modificación que se produce y se transmite en obras como Edipo Rey, donde la verdad, inicialmente perteneciente al poseedor del poder, el tirano, acaba disociándose de este poder y convirtiéndose en su antítesis. La separación radical de poder y saber desde la filosofía platónica, la idea de que

32. Estamos analizando la primera de las conferencias de Foucault ("Nietzsche y su crítica del conocimiento") reunidas bajo el título La verdad y las formas jurídicas. Dice Foucault (2005), pp. 16-17: "La indagación apareció en la Edad Media como forma de investigación de la verdad en el seno del orden jurídico. Fue para saber quién hizo qué cosa, en qué condiciones y en qué momento Occidente elaboró las complejas técnicas de indagación que casi enseguida pudieron ser empleadas en el orden científico y en la reflexión filosófica". 
la verdad se halla separada de la decisión del poder, va a conformar la tradición del pensamiento occidental hasta que -dice Foucault- Nietzsche intuya que detrás de todas las formas del saber se encuentran oscuras pugnas de poder ${ }^{33}$.

Es en la Edad Media cuando lentamente se va abriendo paso una forma de indagación judicial que estará llamada a tener una importancia decisiva en la cultura occidental; forma que tuvo que romper con las tradiciones del derecho germánico, que venía a establecer la justicia como un asunto entre particulares, sin intervención ninguna de "autoridad pública», limitándose la práctica judicial a establecer las formas a las que había de plegarse la venganza entre particulares:

El derecho germánico no opone la guerra a la justicia, no identifica justicia y paz, sino que, por el contrario, supone que el derecho es una forma singular y reglamentada de conducir la guerra entre los individuos y de encadenar los actos de venganza. El derecho es, pues, una manera reglamentada de hacer la guerra ${ }^{34}$.

Un procedimiento -el germánico- que se desarrolla sin ninguna tercera instancia, una instancia neutral que trate de establecer la verdad y sin ninguna forma de indagación de la misma. Los siglos medievales -continúa Foucaultconocen una pugna prolongada entre las tradiciones de derecho romano y las germánicas: cada vez que un Estado se apunta o fortalece reaparece aquél; cuanto mayor es la debilidad de las monarquías más repunta la forma germánica, de forma que el derecho feudal:

es esencialmente germánico, no presenta ninguno de los elementos de los procedimientos de indagación, establecimiento de la verdad de las sociedades griegas o el Imperio romano [...] el litigio entre ambos [particulares] se resolvía por una serie de pruebas aceptadas por los dos y a las que ambos se sometían. Este sistema no era una manera de probar la verdad, sino la fuerza, el peso o la importancia de quien decía ${ }^{35}$.

En tales juicios el juez no establece la verdad sino la "regularidad del procedimiento". A partir del siglo XIII, afirma, se van a producir nuevas formas de justicia y de procedimientos judiciales, en los que no podemos detenernos,

33. "Occidente será dominado por el gran mito de que la verdad nunca pertenece al poder político, de que el poder político es ciego, de que el verdadero saber es el que se posee cuando se está en contacto con los dioses o cuando recordamos las cosas, cuando miramos hacia el gran Sol eterno o abrimos los ojos para observar lo que ha pasado. Con Platón se inicia un gran mito occidental: lo que de antinómico tiene la relación entre el poder y el saber. Si se posee el saber es preciso renunciar al poder; allí donde están el saber y la ciencia en su pura verdad jamás puede haber poder político" (Foucault, 2005, p. 61).

34. Foucault (2005), p. 69.

35. Foucault (2005), p. 71. 
como la indagación, la aparición de la figura del procurador ("representante del soberano, rey o señor"), tercera figura que faltaba en los pleitos, puesto que se va a producir el desplazamiento del ofendido al poder del estado lesionado y la infracción, asociada a la figura anterior, puesto que ahora -además del ofendido- se violenta también la misma ley del Estado. El proceso se va desplazando inexorablemente a la ocupación completa por parte del poder estatal de todo el procedimiento judicial ${ }^{36}$.

La razón de estas nuevas formas de indagación es explicada por Foucault a través de la figura eclesiástica de la visitatio: inicialmente de carácter espiritual y religiosa fue tomando, conforme la iglesia acrecentaba su poder, la forma de investigación acerca de cómo eran administrados los bienes y dirigidos los espíritus en los distintos lugares. Esta forma de saber quedará definitivamente, afirma, como el modelo para el procedimiento judicial ${ }^{37}$. Aparejada a la noción de indagación surge la noción de «infracción» ("cuando un individuo causa daño a otro hay siempre, a fortiori, daño a la soberanía, a la ley, al poder"). Por último -y esto es decisivo en relación con la interpretación de Nietzsche- la noción de daño-infracción Ilevará conjuntamente aparejadas las nociones de falta moral, de «pecado», que para Foucault han Ilegado a nuestros días ${ }^{38}$.

La aportación de las reformas penales ilustradas

Para el derecho penal, las ideas ilustradas supusieron un salto teórico fundamental, por su crítica a las formas y procedimientos punitivos del Antiguo Régimen. Beccaria es tomado como una referencia clave, sin olvidar sus ilustres influencias (Locke, Montesquieu, Helvetius...). El italiano y otros ilustrados son tributarios de las tesis contractualistas, de modo que los delitos sólo habían de ser entendidos como violaciones de ese contrato y la sociedad había de responder a esa ruptura contractual con proporcionalidad al delito e incluso abolir la pena de muerte (salvo en situaciones excepcionales). La certeza de la pena más que su severidad es, o debe ser, el elemento disuasorio frente al delito. Este

36. Una de las grandes finalidades de la apropiación por las monarquías de la justicia es el deseo de recaudación: "Las confiscaciones de bienes son para las monarquías nacientes uno de los grandes medios de enriquecerse e incrementar sus propiedades. Las monarquías occidentales se fundaron sobre la apropiación de la justicia, que les permitía la aplicación de estos mecanismos de confiscación. He aquí el fondo político de esta transformación" (Foucault, 2005, pp. 80-81).

37. Para Foucault todos estos cambios en el procedimiento judicial no son esencialmente progresos en la racionalidad occidental, sino fruto de las transformaciones en las relaciones de poder en el seno de los reinos occidentales (Foucault, 2005, p. 87).

38. Una cuestión que no podemos tratar aquí es la idea de Foucault de que los procedimientos judiciales de la indagación se van a convertir en toda una metodología de obtención de la verdad y procedimiento de las distintas ciencias que van eclosionando en la Edad Moderna. 
mundo ilustrado abominará igualmente de toda la liturgia del castigo público del delincuente convertido en espectáculo de masas.

Con estos planteamientos se introduce el sentido educativo o correctivo de la pena, Ilamado a tener una gran presencia en la filosofía de nuestros sistemas penales. Por supuesto, uno de los elementos más destacados de esta corriente reformista es su repudio a las tradicionales formas de tormento tan habituales hasta entonces.

Sin embargo, el progresismo en materia judicial que se observa en el planteamiento de los teóricos ilustrados va a estar recorrido por una profunda ambigüedad y ambivalencia. Toda la «racionalización» penal que se nos aparece en los albores del siglo XIX no deja de ser calificada por Foucault como "disciplinaria ${ }^{39}$. Para éste, uno de los principios teóricos fundamentales que enuncian las teorías de Beccaria, Bentham o Brissot es éste:

...el crimen, en el sentido penal del término, o más técnicamente la infracción, no ha de tener en adelante relación alguna con la falta moral o religiosa. La falta es una infracción a la ley natural, a la ley religiosa, a la ley moral; por el contrario, el crimen o la infracción penal es la ruptura con la ley, ley civil explícitamente establecida en el seno de una sociedad por el lado legislativo del poder político ${ }^{40}$.

El crimen -como decíamos- es considerado ruptura del contrato social que nos liga a los otros. Éste será el axioma que defina en adelante la teoría del crimen y de la penalidad. Al separar la «falta» del «delito», al considerar que el crimen no es un hecho moral o religioso, el derecho penal no podrá promover el tradicional concepto de «venganza» y su finalidad será producir la «reparación» del daño causado. Para Foucault se abrieron para estos teóricos y otros penalistas al menos cuatro posibilidades de llevar a cabo tal reparación, que fueron: el exilio, la exclusión humillante del infractor, el trabajo forzado y la ley del Talión, en algunos casos. Lo paradójico fue que ninguna de estas fue la «solución» para el hecho delincuencial, sino una que "apenas había sido mencionada por Beccaria y que Brissot trataba de manera muy marginal: [...] el encarcelamiento, la prisión." (Foucault, 2005). La solución reclusional procedía de un ámbito ajeno, parajudicial, que es el de las lettres de cachet de la monarquía absoluta. Y no va a aparecer, pese a Beccaria, con el propósito de respon-

39. "La formación de la sociedad disciplinaria puede ser caracterizada por la aparición, a finales del siglo XVIII y comienzos del XIX, de dos hechos contradictorios, o mejor dicho, de un hecho que tiene dos aspectos, dos lados que son aparentemente contradictorios: la reforma y reorganización del sistema judicial y penal en los diferentes países del Europa y del mundo" (Foucault, 2005, p. 95).

40. Foucault (2005) p. 96. 
der a una «infracción», sino a una intención de corrección del comportamiento individual (donde reaparece la vieja «moralización»):

Una penalidad que no tiene por función el responder a una infracción, sino corregir el comportamiento de los individuos, sus actitudes, sus disposiciones, el peligro que significa su conducta virtual. Esta forma de penalidad [...] no pertenece en realidad al universo del derecho, no nace de la teoría jurídica del crimen ni se deriva de los grandes reformadores como Beccaria. La idea de una penalidad que intenta corregir metiendo en prisión a la gente es una idea policial, nacida paralelamente a la justicia, fuera de ella, en una práctica de los controles sociales o en un sistema de intercambio entre la demanda del grupo y el ejercicio del poder $^{41}$.

¿Por qué se olvidan las lecciones de Beccaria? La respuesta de Foucault tiene que ver con las nuevas formas de riqueza, no necesariamente monetaria, sino material, física, tanto en los ambientes industriales (máquinas, mercancías, stocks ...) como rurales (pequeñas propiedades, desaparición de las tierras comunales, etc.). La cárcel va a ser el sistema más seguro de apartar a los potenciales criminales de toda esta nueva forma de riqueza:

La prisión se impuso simplemente porque era la forma concentrada, ejemplar, simbólica, de todas estas instituciones de secuestro creadas en el siglo XIX. De hecho, la prisión es isomorfa a todas estas instituciones ${ }^{42}$.

\subsection{La justicia burguesa y el sentido de la "pena»}

Cuando Nietzsche reflexiona y escribe sobre la génesis del derecho, la justicia y la penalidad, todas estas novedades teóricas señaladas por Foucault, plasmadas en las prácticas judiciales, ya están plenamente incorporadas al orden liberal-burgués. La prisión es ya la institución penal por antonomasia; todos los demás instrumentos de control y fijación de las poblaciones están ya desarrolladas: el manicomio, la escuela, el ejército, el control de las poblaciones (biopolítica), etc. En este contexto hemos de acercarnos a los juicios que Nietzsche manifiesta sobre la justicia y los procedimientos penales de su propio tiempo. Una opinión extrañada por la falta de sentido de la pena y del modelo de tratamiento delincuencial al que se asoma; radicalmente enfrentada al sistema de justicia y curiosamente inclinada hacia otras formas de justicia, o de autojusticia.

41. Foucault (2005), p. 117.

42. Foucault (2005), p. 144. 


\section{La pena y su finalidad}

Es en el tratado II de La genealogía de la moral -comentábamos- donde Nietzsche desarrolla principalmente su interpretación de la génesis del derecho penal, a partir de este principio evolutivo de la legislación penal: "cuando su poder se acrecienta, la comunidad deja de conceder tanta importancia a las infracciones del individuo" (\#10). Ya vimos como la propia Ley de las XII Tablas romana era considerada por él un avance en la «liberalidad» del derecho, frente a los escrupulosos y tasados castigos y amputaciones de las leyes anteriores. Ahora ya no hay proscripción ni expulsión y el delincuente va a ser protegido precisamente contra los estallidos de cólera que antes se cobraban pronta venganza. Aparece lo que Nietzsche Ilama una voluntad de «arreglo»; aparece la «voluntad» «de considerar que todo delito es pagable en algún sentido, es decir, la voluntad de separar, al menos hasta un cierto grado, una cosa de otra, el delincuente de su acción -éstos son los rasgos que se han impreso cada vez más claramente en el ulterior desarrollo del derecho penal» (ídem). Incluso avanza la posibilidad de que, como todas las cosas buenas sobre la tierra, la justicia acabe "suprimiéndose a sí misma".

Nietzsche critica con dureza a quienes interpretan en su época la pena como poseída de una finalidad cualquiera, como provocada e instaurada, por ejemplo, por la intención de la «venganza» o la «intimidación»; nada tiene que ver -argumenta- la causa de la génesis de una cosa y la utilidad final de ésta; la realidad está en otro lugar, en la «voluntad de poder» (\#12).

A continuación, en el \#13, se detiene a considerar las múltiples posibilidades que la pena supone en el ordenamiento moderno, distinguiendo en ella dos cosas:

por una parte lo relativamente duradero en la pena, el uso, el acto, el «drama», una cierta secuencia rigurosa de procedimientos; por otro lado, lo fluido en ella, el sentido, la finalidad, la expectativa vinculados a la ejecución de tales procedimientos...

El error de pensar en el procedimiento como finalidad de la pena -como comentábamos- es común en moralistas y genealogistas del derecho. Nietzsche sitúa su análisis en el segundo aspecto de la pena, en lo fluido, en el sentido, defendiendo que, a pesar de la aparente unidad, presenta una gran variedad de sentidos y finalidades, que pasa a enumerar:

...pena como neutralización de la peligrosidad, como impedimento de un daño ulterior. Pena como pago del daño al damnificado en alguna forma (también en la forma de una compensación afectiva). Pena como aislamiento de una perturbación del equilibrio, para prevenir la propagación de la perturbación. Pena como inspiración de temor respecto a quienes determinan y ejecutan la pena. Pena como una especie de compensación por las ventajas disfrutadas hasta aquel momento por el infractor (por ejemplo, utilizándolo como esclavo en las minas). Pena como segregación de un 
elemento que se halla en trance de degenerar. Pena como fiesta, es decir, como violentación y burla de un enemigo finalmente abatido. Pena como medio de hacer memoria, bien a quien sufre la pena -la llamada «corrección», bien a los testigos de la ejecución. Pena como pago de un honorario, estipulado por el poder que protege al infractor contra los excesos de la venganza. Pena como compromiso con el estado natural de la venganza, en la medida en que razas poderosas mantienen todavía ese estado y lo reivindican como privilegio. Pena como declaración de guerra y medida de guerra contra un enemigo de la paz, de la ley, del orden, de la autoridad, al que, por considerársele peligroso para la comunidad, violador de los pactos que afectan a los presupuestos de la misma, por considerársele un rebelde, traidor y perturbador de la paz, se le combate con los medios que proporciona precisamente la guerra ${ }^{43}$.

El castigo no proporciona un sentimiento de «culpa»

Nietzsche duda, sin embargo, de la supuesta utilidad de la pena, que sigue siendo el lugar común de quienes creen en la necesidad de castigos para la preservación de la paz social (tengamos en cuenta, que siempre planea sobre todas estas consideraciones la indubitable afirmación de la libertad de la voluntad, y por tanto de la «responsabilidad» plena del infractor). Afirma el filósofo que tal utilidad de la pena, consistente en provocar en el reo el «sentimiento de culpa» es, a la vista de los procedimientos penales modernos, una quimera:

El auténtico remordimiento de conciencia es algo muy raro cabalmente entre los delincuentes y malhechores; las prisiones, las penitenciarías no son las incubadoras en que florezca con preferencia esa especie de gusano roedor [...] Vistas las cosas en conjunto, la pena endurece y vuelve frío, concentra, exacerba el sentimiento de extrañeza, robustece la fuerza de resistencia [...] Si pensamos en los milenios anteriores a la historia del hombre, nos es lícito pronunciar, sin escrúpulo alguno, el juicio de que el desarrollo del sentimiento de culpa fue bloqueado de la manera más enérgica cabalmente por la pena ${ }^{44}$.

En definitiva, para Nietzsche todos los mecanismos de ejecución de la pena no sólo no provocan tal sentimiento de culpa sino que, al advertir el delincuente la frialdad, la planificación con que el «poder» se apodera y castiga su cuerpo, la meticulosidad burocrática con la que diseña y ejecuta sus planes, el resultado sólo puede ser una «extrañeza», una especie de fatalidad en el reo que lo aleja de todo sentimiento de culpa: si yo ejecuté el daño de manera involuntaria, no

43. Nietzsche (1987), pp. 91-92.

44. Nietzsche (1987), p. 93. 
premeditada, primaria, ¿cómo voy a sentirme culpable cuando todo esto se me devuelve multiplicado bajo la más absoluta planificación administrativa? Durante milenios, dice Nietzsche:

[los malhechores] se sometían a la pena como se somete uno a una enfermedad, o a una desgracia, o a la muerte, con aquel valiente fatalismo sin rebelión... ${ }^{45}$.

En definitiva, su conclusión es que:

Lo que con la pena se puede lograr, en conjunto, tanto en el hombre como en el animal, es el aumento del temor, la intensificación de la inteligencia, el dominio de las concupiscencias: y así la pena domestica al hombre, pero no lo hace «mejor» ${ }^{46}$.

\section{Epílogo: ¿una justicia sin moralidad?}
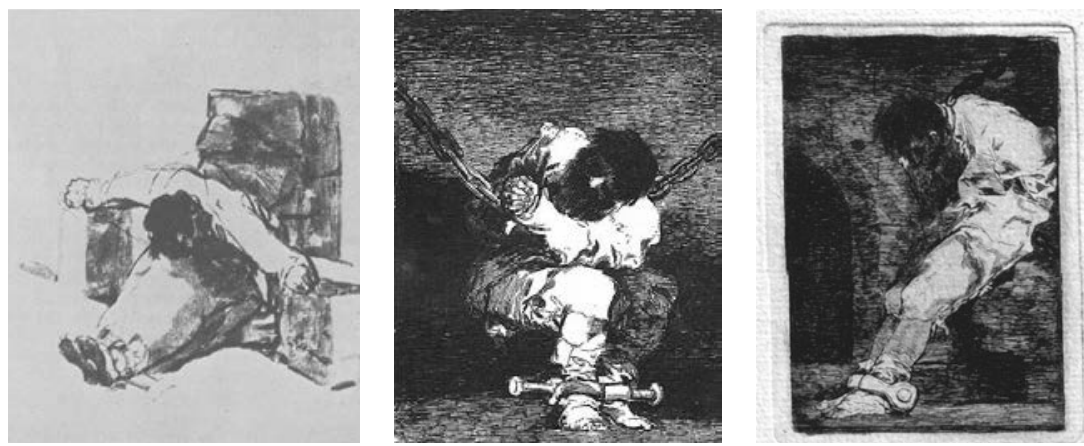

Francisco de Goya, Aguafuertes (1800-1815)

Nietzsche, Foucault, incluso Goya -con sus terribles y patéticos grabados de prisioneros- denunciaron, cada uno en su tiempo y desde su punto de vista, la brutalidad e inutilidad de los procedimientos punitivos modernos. Los grabados del aragonés muestran una sensibilidad plenamente ilustrada -si se quiere coetánea de las ideas penales de Beccaria o psiquiátricas de Pinel-, que no puede comprender ni aceptar el alarde y exhibicionismo en la crueldad que presentan los métodos de castigo de su tiempo. Testigo de un cambio de época que no acaba de producirse, Goya muestra los estragos que sobre los cuerpos muestran las disciplinas del Antiguo Régimen, donde locos, delincuentes e iluminados se

45. Nietzsche (1987), pp. 94-95.

46. Nietzsche (1987), p. 95. 
mezclan desnudamente y sin pudor en las lóbregas cárceles de la monarquía. Décadas más tarde, Nietzsche interrogará a la justicia y a sus procedimientos bajo la lupa implacable del análisis genealógico, preguntándose: ¿para qué tanto castigo inútil? Nada en el procedimiento penal moderno atiende a la finalidad para la que se proyecta; al contrario, todo en él tiende a robustecer la fuerza y la convicción del reo de ser objeto de una «injusticia». Foucault continuará los análisis nietzscheanos interpretando las formas modernas de disciplinariedad, descubriendo que no son los progresos de la Razón, sino las sacudidas en las economías del Poder los que han provocado los desplazamientos en los sistemas penales de Occidente. La cárcel -el castigo moderno por excelencia- no responde a ninguna de las propuestas de recuperación social del malogrado, sólo perpetúa una «necesaria» clase de delincuencia, esencial en la justificación del aparato policial ${ }^{47}$. Además, todavía el Antiguo Régimen ejecutaba con «buena conciencia», como exhibición festiva y ejemplarizante, la atrocidad de un descuartizamiento público. Es el Estado moderno, el estado liberal-burgués, el que castiga a escondidas, con mala conciencia, el que oculta bajo formas asépticas, científicas y médicas, la implacable lógica de la penalidad.

Nietzsche nunca justificó el sentido de los castigos de su tiempo. ¿Para qué castigar? El hombre es un fragmento de fatalidad, es su actuar, no hay voluntariedad de daño. ¿Para qué, entonces, castigar?:

No me gusta vuestra fría justicia; y desde los ojos de vuestros jueces me miran siempre el verdugo y su fría cuchilla.

Decidme, ¿dónde se encuentra la justicia que sea amor con ojos clarividentes?

¡Inventad, pues, el amor que soporta no sólo todos los castigos, sino también todas las culpas!

¡Inventad, pues, la justicia que absuelve a todos, excepto a los que juzgan! ${ }^{48}$.

Intuye, incluso, otra justicia:

¿No cabría imaginar una situación en la que el propio malhechor se declarara culpable y se impusiera públicamente su castigo, con el sentimiento orgulloso de que así honraba la ley que él mismo se había dictado, a saber, el poder del legislador? Algunas veces fallaría, pero con su castigo voluntario, se elevaría por encima de su delito, y no sólo lavaría su culpa, sino que, por su franqueza, su magnanimidad y su paz, produciría con su conducta un beneficio público. Así sería el criminal 
de un futuro posible, cuya condición previa sería la existencia de una legislación futura, basada en la idea de que, en lo grande y en lo pequeño, sólo hay que someterse a la ley que uno mismo se ha dictado. ¡Cuántas cosas habría que intentar aún! ¡Hay tantos futuros por salir a la luz! ${ }^{49}$.

Es verdad, por último, que el derecho nace contra la profunda ley que inspira la voluntad de poder. Desde tal tesis no duda que "desde el punto de vista biológico, a las situaciones de derecho no les es lícito ser nunca más que situaciones de excepción, que constituyen restricciones parciales de la auténtica voluntad de vida, la cual tiende hacia el poder" (Genealogía, T II, \#11). Y, sin embargo, a pesar de ser la legislación una especie de "contranaturaleza», hay en Nietzsche -como hemos visto- una profunda justificación del derecho, como acertadamente vio Paul Valadier ${ }^{50}$. El derecho es y ha sido una buena cosa en la tierra; ha frenado y reconducido los instintos de venganza, que aún asoman en las multitudes airadas que por doquier lincharían bajo el impulso emocional del acontecimiento; ha sido una fuerza activa, ha impersonalizado la pena, ha suavizado en general sus métodos. Pero -como no puede creer en la inocencia de la voluntad- no puede dar el último y definitivo paso: no castigar, perdonar, suprimirse a sí mismo, como hacen todas las cosas buenas en la tierra. Cierto es que mientras Nietzsche se dedicaba a demoler los conceptos de «verdad» y «moralidad», mantuvo siempre en pie un alto concepto de la justicia ${ }^{51}$.

\section{Bibliografía}

BARAHONA, R., "El pensamiento jurídico de F. Nietzche: una posición existencial ante el derecho", Revista de Filosofía de la Universidad de Costa Rica 20 (1967), pp. 41-54.

CARRASCO JIMÉNEZ, E., "Nietzsche y su visión del derecho penal", Polis, Revista de la Universidad Bolivariana 7 (21, 2008), pp. 203-227.

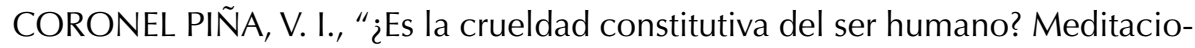
nes a partir de Nietzsche y Freud, Mutatis Mutandis: Revista internacional de Filosofía 5 (2015), pp. 87-98.

DÁVILA LONDOÑO, L. F., "El Derecho y la violencia: una polémica relación pensada desde Nietzsche y Foucault", Revista CES Derecho 6 (2, 2015), pp. 108-120.

DELUMEAU, J., La confesión cristiana y el perdón, Barcelona, Altaya, 1997.

FOUCAULT, M., Nietzsche, la genealogía, la historia, Valencia, Pre-Textos, 2004.

49. Nietzsche (2000), p. 171.

50. Valadier (1998).

51. Es lo que afirma con razón R. Marquisio (2007). 
FOUCAULT, M., Nietzsche, Freud, Marx, Valencia, Barcelona, Cuadernos Anagrama, 1981.

FOUCAULT, M., La verdad y las formas jurídicas, Barcelona, Gedisa, 2005.

LEMM, V., Nietzsche y el pensamiento político contemporáneo, Santiago de Chile, FCE, 2013.

MARQUISIO, R., "Nietzsche y la justicia sin moral”, Actio 9 (2007), pp. 57-73.

NIETZSCHE, F., Humano, demasiado humano I y II (2 vol.), Madrid, Akal, 1996.

NIETZSCHE, F., Aurora, Madrid, Biblioteca Nueva, 2015.

NIETZSCHE, F., La Ciencia jovial, Madrid, Biblioteca Nueva, 2001.

NIETZSCHE, F., Así habló Zaratustra, Madrid, Alianza Editorial, 2011.

NIETZSCHE, F., La genealogía de la moral, Madrid, Alianza Editorial, 1996.

PACHÓN SOTO, D., "Nietzsche, el estado y el derecho", Pensamiento jurídico, 16 (2006). Disponible en: http://revistas.unal.edu.co/index.php/peju/article/ view/40375.

QUINTANO RIPOLLÉS, A., "Ideas jurídicas de Nietzsche", Anuario de Filosofía del Derecho, 5 (1957), pp. 175-194.

VALADIER, P., Nietzsche : cruauté et noblesse de droit, Paris, Michalon, 1997.

VALADIER, P., Nietzsche y la crítica del cristianismo, Madrid, Cristiandad, 1982. 